\section{Anstieg positiver Hauttests durch zunehmende Histamin-Sensitivität?}

In den letzten Jahren ließ sich bei Kindern eine Zunahme der Soforttyp-Reaktionen im Hauttest auf häufige Allergene beobachten. Eine Gruppe italienischer Forscher prüfte nun, ob eine Änderung der Hautreagibilität gegenüber Histamin dahinter stecken könnte.

\begin{abstract}
A n drei epidemiologischen Studien (1983-7, 1992, 1996) in der Provinz Viterbo nahmen insgesamt 536 Schüler im Alter von neun oder 13 Jahren teil. In beiden Altersgruppen zeigte sich im Zeitverlauf eine signifikante Größenzunahme der durch Histamin $(10 \mathrm{mg} / \mathrm{ml})$ im Pricktest ausgelösten Quaddel. Ebenso ergab die Verteilung der Quaddel-Durchmesser für beide Altersgruppen in den drei aufeinanderfolgenden Untersuchungen eine Verschiebung in Richtung eines größeren Quaddel-Durchmessers ( $\mathrm{p}<0,001)$.
\end{abstract}

Auch der Anstieg der Dosis-WirkungsKurve, die mit drei Histamin-Konzentrationen $(0,2 \mathrm{mg} / \mathrm{ml}, 1 \mathrm{mg} / \mathrm{ml}$, und 10 $\mathrm{mg} / \mathrm{ml}$ ) überprüft wurde, war 1996 signifikant steiler als in den Jahren 1983 bis 1987 ( $p<0,001)$. Die Autoren gehen davon aus, dass ein Zusammenhang zwischen der Größenzunahme der Histamin-Quaddeln und dem vermehrten Auftreten positiver Hauttests auf häufige Allergene besteht. Die Forschergruppe stellte fest, dass die gleiche durch Allergen aus Mastzellen freigesetzte Menge Histamin 1996 eine etwa doppelt so große Quaddel erzeugte wie zehn bis 15 Jahre zuvor. Dies würde nach Ansicht der Autoren bedeuten, dass eine früher als grenzwertig eingestufte Hautreaktion nun als deutlich positiv erscheint.

\section{Fazit}

Die deutliche Größenzunahme der Histamin-Quaddel im Zeitverlauf könnte eine Erklärung für die Berichte über eine Zunahme positiver Hauttests in den letzten Jahren bieten. Über die Ursachen dieser gesteigerten Hautreagibilität auf Histamin sind derzeit nur Mutmaßungen möglich. Es stellt sich auch die Frage, ob die erhöhte Reagibilität auf Histamin nur die Haut oder auch andere Organe betrifft.

Dr. A. Niedermeier

Ronchetti $R$ et al. Changes over 13 years in skin reactivity to histamine in cohorts of children aged 9-13 years. Allergy 2001; 56: 436-41.

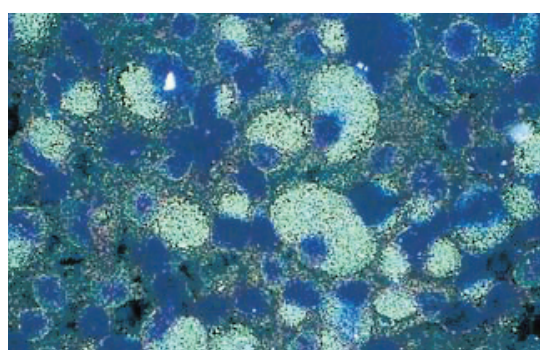

Chlamydien mit den charakteristischen Einschlusskörperchen

in den Lungengewebsbiopsien von Asthmatikern mit positiven PCR-Ergebnissen eine signifikant höhere Mastzelldichte und die Tendenz zu einer höheren Zahl von T-Lymphozyten im Vergleich zu den Patienten mit negativem PCR-Ergebnis.

\section{Fazit}

Bei einer erheblichen Anzahl von Patienten mit chronischem Asthma bronchiale finden sich Mykoplasmen und/oder Chlamydien in den Atemwegen. Bemerkenswert ist die Assoziation dieses Befundes mit einem erhöhten Zahl von Mastzellen im Lungengewebe. Es stellt sich die Frage nach einem kausalen Zusammenhang bei der AsthmaEntstehung: Verschiedene Autoren dis- kutieren einen protektiven Effekt einer der Sensibilisierung vorausgehenden Infektion, während das Gegenteil der Fall ist, wenn die Atemwegsinfektion nach einer Sensibilisierung auftritt. Die sich abzeichnende Bedeutung von Mykoplasmen oder Chlamydien für die $\mathrm{Pa}$ thophysiologie des Asthma bronchiale ist interessant. Werden diese Erkenntnisse bestätigt, könnte dies auch ein Weg zu neuen Therapiemöglichkeiten sein.

Dr. A. Niedermeier

Martin RJ et al. A link between chronic asthma and chronic infection. J Allergy Clin Immunol 2001; 107: 595-601. 